\title{
FAINTING AND FITS IN CARDIAC INFARCTION
}

\author{
BY \\ HAROLD COOKSON \\ Received September 18, 1942
}

Thoracic pain, the cardinal symptom, may be absent in acute cardiac infarction, the best known equivalents being dyspnœa or other signs of congestive failure, and more rarely abdominal and cerebral syndromes. With pain of great intensity, syncopal symptoms may occur also as a result of cerebral vascular complications, and sudden death, which is not infrequent in this condition, can be regarded as the extreme form of syncopal attack. But occasionally disturbances of consciousness are a most prominent feature of the attack apart from all these conditions, with pain absent or displaced into the background. This is especially so at the onset of the attack. Many papers on cardiac infarction without much or any pain have referred mainly to patients with congestive failure, and disturbances of consciousness have not often been mentioned. (Bean \& Read, 1942; Boyd \& Werblow, 1937; East \& Bain, 1928; Gorham \& Martin, 1938; Gross \& Sternberg, 1939; Hay, 1933; and Kennedy, 1937.) In the present series, seen among some 200 cases of acute cardiac infarction, syncopal symptoms were prominent in 15 , in 10 at the onset and in 5 in the course of the illness.

\section{Syncopal ATtACKS AT THE ONSET}

Of 10 patients in whom cardiac infarction was ushered in by a syncopal attack (Table I) 5 were men and 5 women. The average age was advanced, five being 70 or more. Consciousness was partly or completely lost in all, but no convulsion was observed. The patient's appearance was that of severe shock or peripheral circulatory failure, the radial pulse being usually imperceptible, the skin pale and moist, and vomiting almost invariable. Of eight patients in whom the heart rate was known during the syncope, it was slow (50 or less) in five, in two there was sinus tachycardia, and in one with ventricular tachycardia the rate was 160 . No cardiogram was obtained during these initial symptoms, but in one instance (Case 7) in which sinus bradycardia was recorded, pallor and a complaint of faintness while the tracing was being taken coincided with a drop in rate to about 24 a minute. In most of the other cases cardiograms taken between the second day and sixth week of the illness showed abnormal rhythms. In one and probably in a second there was A-V nodal rhythm, in two auricular flutter, in one auricular fibrillation, and in one ventricular tachycardia. The site of infarction could be located in nine; six in the posterior wall, three in the anterior wall, and the remaining 
one probably also of the anterior type. Pain was absent or slight in five, moderate in four, and severe in one; in two it was confined to the abdomen. Six patients died between the first day and the fourth month, three from congestive failure, one after a hemiplegia, one suddenly, and one with symptoms of shock. The four survivors, who have lived an average of about three years since the attack, were with one exception the youngest of the group. None of these patients had previously suffered from any serious cardiac symptoms. In two there had been previous symptoms of cerebral origin and in five a high blood pressure reading was obtained at some time.

TABLE I

SyNCOPE AT ONSET IN CARDIAC INFARCTION

\begin{tabular}{|c|c|c|c|c|}
\hline $\begin{array}{l}\text { Case No., } \\
\text { Sex, and } \\
\text { Age }\end{array}$ & Attack & Rhythm Recorded & $\begin{array}{l}\text { Site of Infarction } \\
\text { (above) and Degree } \\
\text { of Pain (below) }\end{array}$ & Result \\
\hline 1. M./72 & $\begin{array}{l}\text { Unconscious; no } \\
\text { pulse; heart } 48 .\end{array}$ & $\begin{array}{l}\text { Nodal rhythm } \\
\text { days later). }\end{array}$ & $\begin{array}{l}\text { Anterior. } \\
\text { None. }\end{array}$ & $\begin{array}{l}\text { Failure. } \\
\text { Died 8th day. }\end{array}$ \\
\hline 2. M./62 & $\begin{array}{l}\text { Fainting; no } \\
\text { pulse; heart } 35 .\end{array}$ & $\begin{array}{l}\text { Nodal rhythm; } \\
\text { short runs V.P.T. } \\
\text { (six weeks after } \\
\text { onset). }\end{array}$ & $\begin{array}{l}\text { Posterior. } \\
\text { Moderate. }\end{array}$ & $\begin{array}{l}\text { Failure. } \\
\text { Died } 7 \text { th week. }\end{array}$ \\
\hline 3. F./79 & $\begin{array}{l}\text { Fainting; } \\
\text { ? heart rate. }\end{array}$ & $\begin{array}{l}\text { Auricular flutter } \\
\text { (2nd day). }\end{array}$ & $\begin{array}{c}\text { Posterior. } \\
\text { Severe (abdomen). }\end{array}$ & $\begin{array}{l}\text { Hemiplegia. } \\
\text { Died 15th day. }\end{array}$ \\
\hline 4. M./44 & $\begin{array}{l}\text { Fainting; } \\
\text { ? heart rate. }\end{array}$ & $\begin{array}{l}\text { Auricular flutter } \\
\text { (20th day). }\end{array}$ & $\begin{array}{l}\text { Posterior. } \\
\text { None. }\end{array}$ & $\begin{array}{l}\text { Well } 2 \text { years } \\
\text { later. }\end{array}$ \\
\hline 5. F./72 & $\begin{array}{l}\text { Fainting; no } \\
\text { pulse; heart } 44 .\end{array}$ & $\begin{array}{l}\text { Auricular fibrilla- } \\
\text { tion (8th hour). }\end{array}$ & $\begin{array}{l}\text { Anterior. } \\
\text { Moderate. }\end{array}$ & $\begin{array}{l}\text { Died suddenly } \\
\text { 1st day. }\end{array}$ \\
\hline 6. F./55 & $\begin{array}{l}\text { Fainting; } \\
\text { pulse } 160 .\end{array}$ & $\begin{array}{l}\text { Ventricular tachy- } \\
\text { cardia (4th day). }\end{array}$ & $\begin{array}{l}\text { ? Anterior. } \\
\text { Slight (abdomen). }\end{array}$ & $\begin{array}{l}\text { Failure. } \\
\text { Died 4th } \\
\text { month. }\end{array}$ \\
\hline 7. M./45 & Fainting. & N.R. rate 33 . & $\begin{array}{l}\text { Posterior. } \\
\text { Slight. }\end{array}$ & $\begin{array}{l}\text { Well } 1 \text { year } \\
\text { later. }\end{array}$ \\
\hline 8. F./70 & $\begin{array}{l}\text { Fainting; } \\
\text { pulse } 50 .\end{array}$ & $\begin{array}{l}\text { N.R.; rate } 75 \text { (10th } \\
\text { day). }\end{array}$ & $\begin{array}{l}\text { Posterior. } \\
\text { None. }\end{array}$ & $\begin{array}{l}\text { Well } 3 \text { years } \\
\text { later. }\end{array}$ \\
\hline 9. M./53 & Fainting. & $\begin{array}{l}\text { N.R., S.A.; rate } 70 \\
\text { (2nd day). }\end{array}$ & $\begin{array}{l}\text { Posterior. } \\
\text { Moderate. }\end{array}$ & $\begin{array}{l}\text { Well } 5 \text { years } \\
\text { later. }\end{array}$ \\
\hline 10. F./82 & Fainting. & $\begin{array}{l}\text { N.R.; rate } 120 \text { (2nd } \\
\text { day). }\end{array}$ & $\begin{array}{l}\text { Anterior. } \\
\text { Moderate. }\end{array}$ & Died 3rd day. \\
\hline
\end{tabular}

N.R.-Normal rhythm.

S.A.-Sinus arhythmia.

V.P.T.-Ventricular paroxysmal tachycardia.

Case 1.* An active man of 72, previously well except for moderate hypertension and some transient cerebral symptoms one year before, was found unconscious just after he had gone to bed. When his doctor arrived, radial pulse imperceptible, some vomiting, heart rate about 48 , and sounds only just audible. Next day the rate rose to 55 and remained there until death. Congestive failure developed within a day or

* All patients were seen in private practice and post-mortem examination was not possible in any. 
two. The rhythm (Fig. 1) has been classed as nodal but resembles those recorded from subjects free of heart disease with physiological short P-R bundle branch block curves. Any of the interpretations that have been suggested for such curves would apply equally to this one. There are changes in the RS-T segments suggesting anterior infarction, though in lead IVR they are atypical.

Case 2. A man, aged 62, fell down in a faint when walking home. When seen by his doctor, he was sweating, bluish-gray in colour, some epigastric pain, radial pulse imperceptible, heart rate about 35. After vomiting, condition improved and next day perfectly well; heart rate still 35. After ten days allowed up but ten days

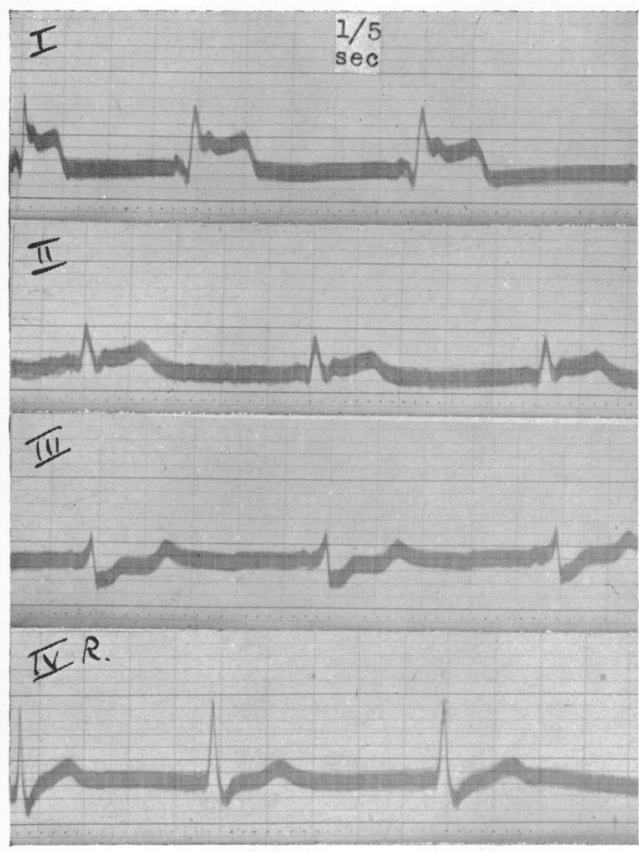

FIG. 1.-Case 1. Taken on the eighth day, a few hours before death. Regular rhythm, rate 60; short P-R interval, wide QRS complex.

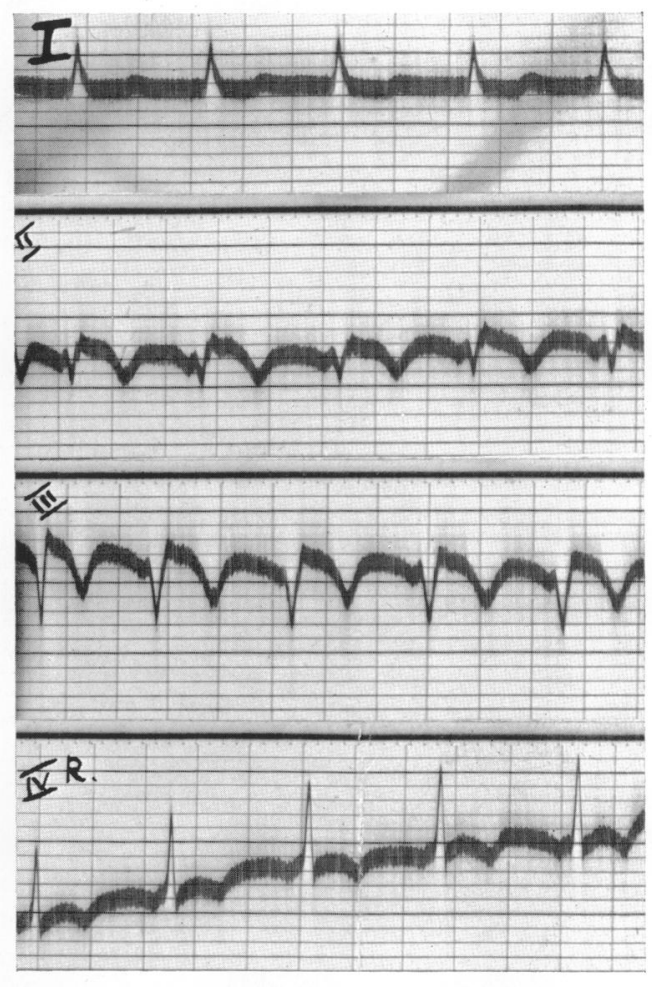

FIg. 2.-Case 4. Taken on the twentieth day. Auricular flutter (A. about 230 with $2: 1$ block); RS-T and T changes suggesting posterior infarction.

later some abdominal discomfort, dyspnœa, œdema in the feet and back, and rales at the lung bases. In the sixth week, the B.P. was 180/90, and there was severe orthopnœa and systemic venous congestion. Cardiogram: a basal ventricular rhythm, probably nodal, rate of 60 to 70, $\mathbf{P}$ wave absent; ventricular extrasystoles, some interpolated, sometimes multiple; left axis deviation, QRS low voltage; RS-T depressed in lead I, elevated in lead III; posterior infarction. Two days later the patient vomited and died suddenly.

Case 3. A woman of 79, previously quite well, fainted in a lavatory. When seen by her doctor, severe upper abdominal pain, which next day was felt only in the left iliac fossa; there was dyspnœa, cold skin, sweating, and cyanosis; many fine rales at the left lung base; B.P. 120/100. Cardiogram: auricular flutter, A, 240 with variable $2: 1,3: 1$ block, right axis deviation; elevation of RS-T segment in all leads, $T_{2}$ and $T_{3}$ inverted, $Q_{3}$ present. Posterior infarction. Good progress until 
the twelfth day when a sudden left hemiplegia was followed by her death three days later.

Case 4. A healthy man of 44 felt short of breath while playing golf; later became faint, vomited, and had a cold sweat. During next few days, slight icteric tint of the skin, systolic B.P. under 100, and some dyspnœa. Fig. 2 suggested posterior infarction. He was given digitalis, and 13 days later cardiogram showed normal rhythm, rate $85, \mathrm{P}-\mathrm{R}$ interval $0.35 \mathrm{sec}$, frequent ventricular extrasystoles some interpolated, RS-T deviation and T inversion less. Good progress, and well two years later.

Case 5. A woman of 72, previously well, fainted and then vomited. When seen by her doctor soon after, radial pulse imperceptible, but later palpable, rate 44 ; complained of pain behind mid-sternum, in jaw, and in left arm. Cardiogram taken nine hours after onset showed auricular fibrillation, ventricular rate about 165 , QRS complex wide, $R$ absent in lead IVR; RS-T deviation upward in leads I and IVR, downward in leads II and III. Anterior infarction. A few minutes after this was taken she died suddenly.

Case 6. A woman of 55 with hypertension for some years, hemiplegia two years before, and transient blindness one year before. In bed with epigastric pain for two or three weeks. Sudden faint attack with ashen colour, heart rate of 160 , and orthopnœa. Four days later, Fig. 3 showed ventricular tachycardia, and two days

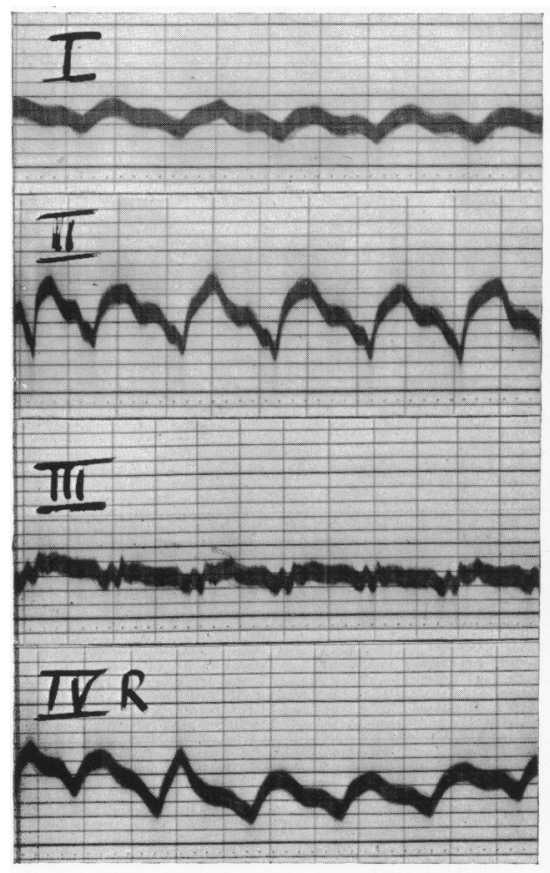

A

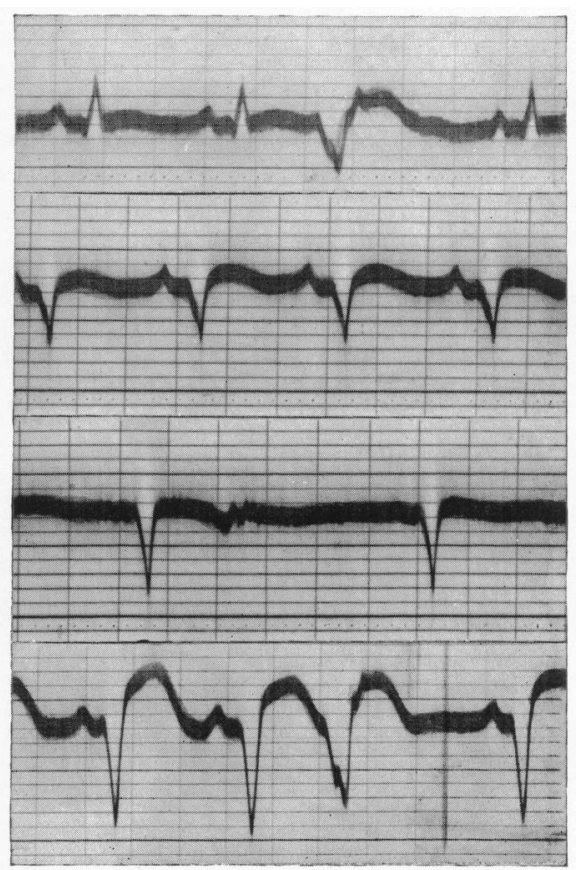

B

Fig. 3.-Case 6. (A) Taken on the fourth day. Ventricular tachycardia, rate 155. (B) Two days later after 15 grains of quinidine. Normal rhythm, rate $95 ; R$ wave absent in leads II, III, and IVR; upward deviation of RS-T in all leads; occasional ventricular
extrasystoles.

later after quinidine, normal rhythm. Periodic dyspnœa during the following weeks with a right pleural effusion. Then œdema of the legs which cleared up, but after increasing weakness the patient died in the fourth month.

Case 7. A man of 45 had some sternal discomfort after a day's shooting; he slept well and felt well next morning but fainted after a bath. When seen by his doctor, colour gray and some upper sternal discomfort; pulse rate was 40 . Six hours 
later comfortable, apex beat much out and heaving; B.P. 140/80. Fig. 4 showed sinus rhythm, at rate of 33 a minute. During the tracing heart rate varied and at the slower rate (under 24), pallor and faintness. Cardiogram nine weeks later, similar except for rate of 75 , no deviation of RS-T segments, $T_{2}$ just negative, $T_{3}$ inverted. Well 15 months after the attack.

Case 8. A woman of 70 fainted without obvious cause; no pain but some sensation of wanting to defæcate; when seen, pulse rate 50 regular. Known to have had B.P. of $220 / 100$ four years before. On the tenth day, comfortable, with no signs

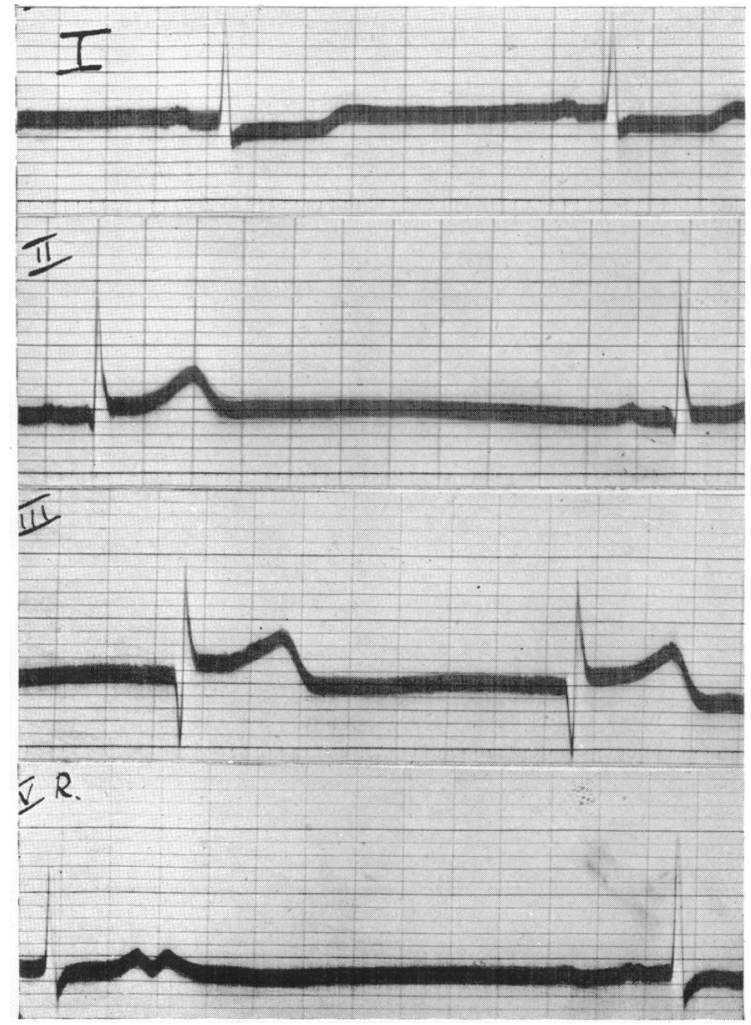

FIG. 4.-Case 7. Sinus rhythm, rate 33; P-R interval $0 \cdot 20$ sec.; $P$ wave notched; small $Q_{2}$, large $Q_{3}$, QRS complex rather wide; RS-T depression in leads I and IVR, elevation in II and III; suggesting posterior infarction.

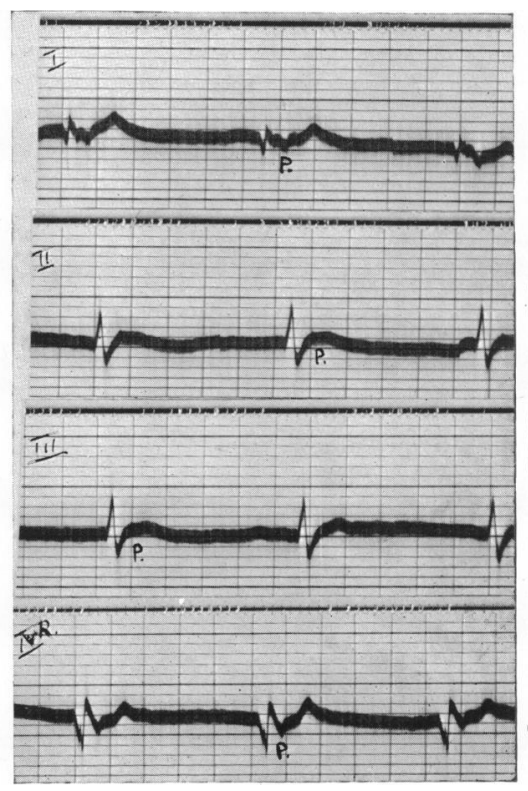

Fig. 5.-Case 11. Taken ten hours after the onset. Rhythm almost regular, rate 55; QRS, 0.1 sec.; negative $P$ following QRS; RS-T slightly depressed in leads I and IVR, slightly elevated in leads II and III. Nodal rhythm; intraventricular block; posterior infarction.

of failure; B.P. 230/110. EC. showed normal rhythm, rate 80, QRS complex $0.09 \mathrm{sec}$., slight depression of RS-T in leads I, II, and IVR, $\mathrm{T}_{2}$ diphasic, $\mathrm{T}_{3}$ inverted; small $\mathrm{Q}_{3}$; occasional ventricular extrasystoles. Three years later fairly well but auricular fibrillation; $Q_{3}$ no longer present and $T_{2}$ and $T_{3}$ upright.

Case 9. A man of 53, a chronic alcoholic, had fainted and then complained of upper sternal pain. When seen immediately by his doctor, sweating and colour ashen; pulse 68, regular. Next day felt well; B.P. 110/80, liver enlarged, no signs of failure. Cardiogram: normal rhythm, rate $70, \mathrm{QRS}$ complex low voltage, $\mathrm{T}_{2}$ just negative, $T_{3}$ inverted. Posterior infarction. Good recovery and no cardiac symptoms five years later.

Case 10. A woman of 82 fainted and had pain between shoulders with radiation into both arms. In bed next day, comfortable except for aching in back. No 
dyspnœa; apex beat just out, loud systolic murmur at apex; B.P. 80/60. A cardiogram showed normal rhythm, rate 120 a minute; a very small $\mathrm{R}$ in lead IVR; slight depression of RS-T in leads II and III, and elevation in IVR; T wave in leads I and IVR just negative; suggests anterior infarction. Death occurred on the third day.

\section{Syncopal Attacks in the Course of Cardiac Infarction}

Observations were made on five patients with disturbances of consciousness in the course of cardiac infarction that had begun in a typical way with anginal pain (Table II). There were four men and one woman, and the average age was 69. In two there was loss of consciousness without any fit; the other three had Stokes-Adams attacks. The faint or fit occurred on the first day of the illness in two cases, while the latest was on the tenth day. Cardiograms showed nodal rhythm immediately before and after the attack in one; complete heart block during the attack and two hours after the attack respectively in two; sinus tachycardia and multiple auricular extrasystoles in one a few minutes after an attack; and sinus tachycardia between attacks in one. In four cases the site of the infarction was posterior; in the remaining one it could not be determined. Chest pain was moderate and of typical distribution in four cases, but in one it was severe and confined to an area below the left scapula throughout the illness. All five patients died within 29 days of the onset of the infarction. Previous anginal attacks had been experienced by two of them.

TABLE II

Syncope in the Course of Acute Cardiac Infarction

\begin{tabular}{|c|c|c|c|c|}
\hline $\begin{array}{l}\text { Case No., } \\
\text { Sex, and } \\
\text { Age }\end{array}$ & Attack & Rhythm Recorded & $\begin{array}{c}\text { Site of Infarction } \\
\text { (above) and Degree } \\
\text { of Pain (below) }\end{array}$ & Result \\
\hline 11. F./79 & $\begin{array}{l}\text { Stokes-Adams (1st } \\
\text { day). }\end{array}$ & $\begin{array}{l}\text { Nodal rhythm (be- } \\
\text { fore and after). }\end{array}$ & $\begin{array}{l}\text { Posterior. } \\
\text { Moderate (chest). }\end{array}$ & Died 1st day. \\
\hline 12. M./67 & Fainting (1st day). & $\begin{array}{l}\text { C.H.B. (2 hours } \\
\text { after attack). }\end{array}$ & $\begin{array}{c}\text { Posterior. } \\
\text { Moderate (chest). }\end{array}$ & Died 1st day. \\
\hline 13. M./69 & $\begin{array}{l}\text { Stokes-Adams } \\
\text { (10th day). }\end{array}$ & C.H.B. (in attack). & $\stackrel{?}{\text { Moderate (chest). }}$ & Died 29th day. \\
\hline 14. M./69 & Fainting (3rd day). & $\begin{array}{l}\text { Sinus tachycardia } \\
\text { and Aur. P.C. } \\
\text { (after attack). }\end{array}$ & $\begin{array}{c}\text { Posterior. } \\
\text { Moderate (chest). }\end{array}$ & Died 4th day. \\
\hline 15. M./62 & $\begin{array}{l}\text { Stokes-Adams (5th } \\
\text { day). }\end{array}$ & $\begin{array}{l}\text { Sinus tachycardia } \\
\text { (between attacks). }\end{array}$ & $\begin{array}{c}\text { Posterior. } \\
\text { Severe (back). }\end{array}$ & Died 10th day. \\
\hline
\end{tabular}

C.H.B.-Complete heart block.

Aur. P.C.-Auricular premature contractions.

Case 11. A woman of 79 with old-standing hypertension, but a normal cardiogram five years before, and no cardiac symptoms. Retrosternal pain one morning. through to the back with numbness of the forearm and wrists, lasted until relieved by morphia five hours later. Heart rate then 90 regular; B.P. 220/110. In after- 
noon speech incoherent but had recovered by evening. Fig. 5 , taken ten hours after onset, showed nodal rhythm, intraventricular block, and posterior infarction. Immediately after this curve had been taken, the patient became strange in manner; and vomiting, pallor, and stupor followed, and then a sudden brief tonic contraction of all limbs. The patient was then quite unconscious and cold and clammy, and the radial pulse could not be felt. The electrodes were still attached, and Fig. 6 showing
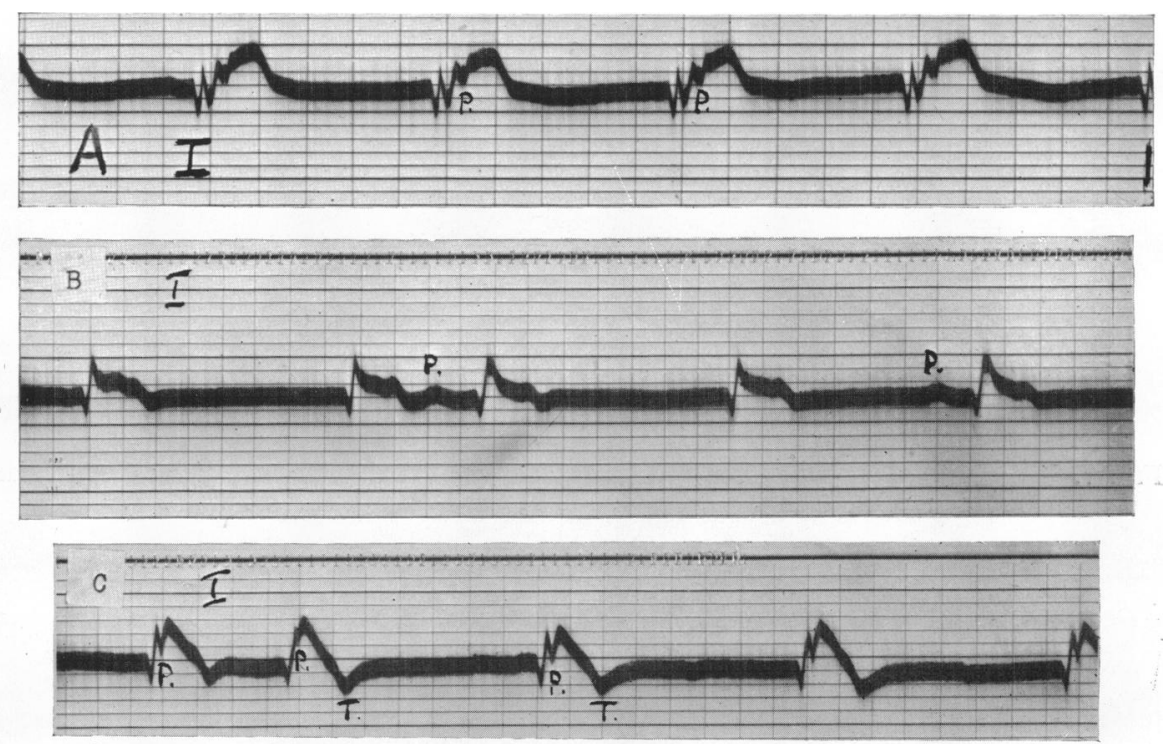

FIG. 6.-Case 11. (A) Nodal rhythm, rate 60; QRS, W-shaped; elevation of RS-T. (B) Taken ten minutes after (A). Change in the form of QRS; RS-T elevation less, with a very small negative $T$ wave; a shallow negative $P$ wave in the RS-T segment; the third and fifth cycles represent sinus beats with prolonged P-R interval.

(C) Taken after breathing had stopped. Nodal rhythm with one premature beat, increased upward deviation of RS-T and deeper inversion of T; rate about 40 a minute.

nodal rhythm was taken immediately. The rate continued to decrease and the voltage of the complexes to diminish until they finally ceased 25 minutes after the onset of the attack.

Case 12. A man of 67 woke at 6 a.m. with pain in the mid-chest radiating into both arms, neck, and jaw. He stayed in bed and at 3 p.m. was found unconscious. When seen by his doctor soon after, there was pallor, pulse imperceptible, heart irregular, rate 120. After a short time the pulse could be felt with a rate of 56. At 5 p.m. his skin was pale yellow and moist; some dyspnœa, cervical veins engorged; abdomen a little distended; apex beat heaving in anterior axillary line; heart sounds very distant; B.P. 100/60. Complete heart block (Fig. 7). Death occurred the same day. There was a history in this case of anterior infarction 5 years before and of paroxysmal dyspnœa on and off for 4 years.

Case 13. A man of 69 with effort angina for 18 months and a prolonged attack of rest angina 8 months previously. On the tenth day of a second attack of prolonged rest angina, Stokes-Adams attacks began and recurred at intervals of a few minutes. Between the seizures the pulse was irregular, rate about 100; during them the radial pulse could not be felt but as consciousness was regained the beating was resumed at the rapid rate. Fig. 8 taken between attacks shows partial heart block, and the lower strip of lead III taken during a Stokes-Adams attack shows complete heart block. Pulmonary congestion developed and death occurred immediately after a Stokes-Adams attack 19 days later. 


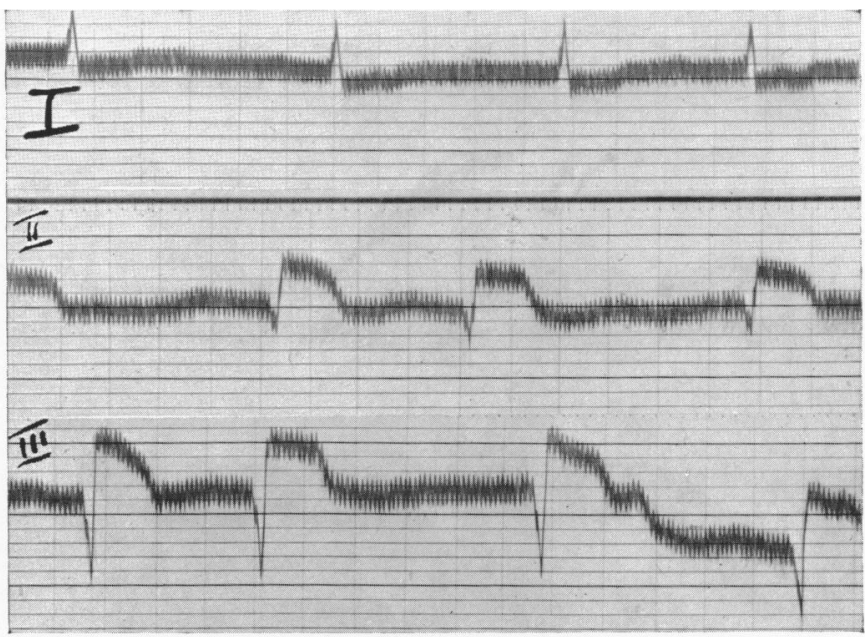

Fig. 7.-Case 12. Complete heart block with an occasional premature beat; ventricular rate 56; changes in QRS, RS-T, and T, suggesting posterior infarction.
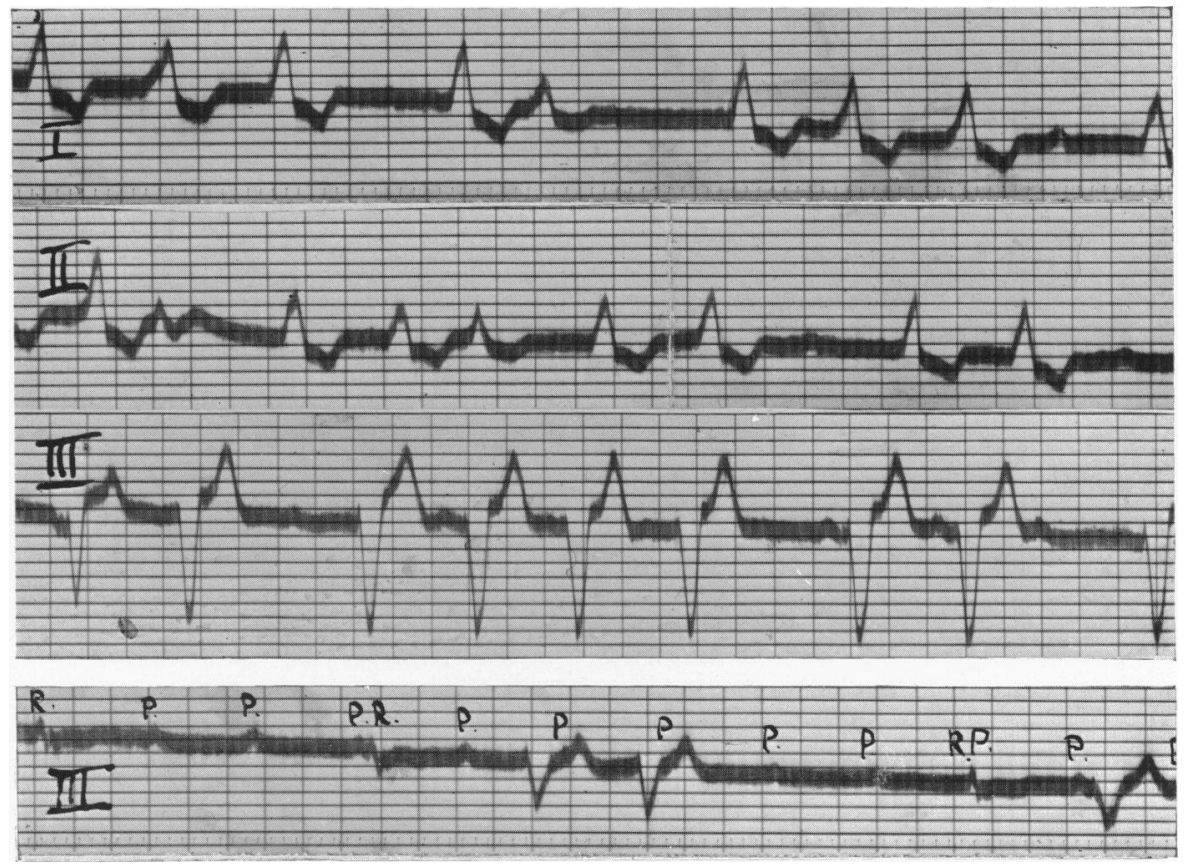

FIG. 8.-Case 13. Partial heart block and intraventricular block; A about 110; V about 100 ; occasional ventricular extrasystoles. The lower strip of lead III taken during a Stokes-Adams attack shows complete heart block; A, 110; V, 34: QRS and T very low voltage: the third, fourth, and sixth ventricular complexes represent a response to supraventricular impulses or alternatively ventricular extrasystoles. 
Case 14. A man of 69 after three days of pain in the chest and left arm had repeated brief fainting attacks. There was recurrent vomiting but little dyspnœa; apex beat heaving in the anterior axillary line; radial pulse barely palpable, systolic murmur at the apex. Cardiogram on the third day showed sinus tachycardia with short runs of auricular extrasystoles; rate 135 per minute; RS-T depression in lead I, elevation in lead III; T positive in leads I and IVR, inverted in leads II and III; $\mathrm{Q}$ of $4 \mathrm{~mm}$. amplitude in lead III. Posterior infarction. Death on the fourth day.

Case 15. A man of 62: slight chest pain for some months and pain below left scapula for five days. Pulse 120, completely irregular. Two days later dyspnœea, vomiting, irregular tachycardia, and persistence of the back pain which became worse while being examined, and the pulse was felt to become progressively slower and more feeble; there was extreme pallor, respiration stopped, and there was a generalized convulsion lasting a few seconds. Consciousness was regained immediately, the pulse returning with a rate of 108 and still completely irregular. The back pain was again distressing and was not controlled until 3/4 grain morphia had been given within half an hour. Slight pyrexia. B.P. 150/95, apex beat not palpable; no signs of failure. Cardiogram 8 hours later showed normal rhythm, rate 110 a minute; $P-R$ interval less than 02 sec.; $T_{1}$ just positive, $T_{2}$ flat, $T_{3}$ just negative. Next day another Stokes-Adams attack, again preceded by intense pain in back. Some bloodstained sputum. On succeeding days further Stokes-Adams attacks and death on tenth day. Two other cardiograms taken between the attacks also showed sinus tachycardia with normal $A-V$ conduction; there were progressive changes in the $\mathrm{QRS}$ complexes and $\mathrm{T}$ waves, consistent with posterior infarction.

\section{Discussion}

The syncope that sometimes marks the onset of cardiac infarction is generally accompanied by severe shock or peripheral circulatory failure, with an abnormally slow heart rate. It may come on very abruptly so that the patient has no warning before he falls to the ground. Anginal pain may be mild or absent throughout. Congestive failure follows, not infrequently, after a short interval. The prognosis in cardiac infarction with syncopal onset, judging from the ten cases reported here, among which there were six deaths within three months, is much graver than usual. However, the average age of these fatal cases was advanced, and the mortality of acute cardiac infarction in the elderly is very high. To produce the sudden syncope of the onset several factors are probably operating, but the principal one must be a nervous reflex leading to vasomotor depression and vagal stimulation causing bradycardia. A subsidiary effect is the reduced force and efficiency of systole that results from the inactivity of the infarcted area of myocardium. There is also the possibility of a direct ischæmic effect on the auricles causing bradycardia and abnormal rhythms. If so, it would fit in with the infarction being more often of the posterior type (excluding one case with ventricular tachycardia there were six posterior and three anterior infarctions), since according to Gross (1921) the right coronary artery takes a larger share in the arterial supply to the auricles. Further support for such an effect is the finding, both at the time of the attacks and later, of depression of the pacemaker and of auricular fibrillation and flutter. Cushing et al. (1942) found an abnormal auricular mechanism in 17 of 23 cases of auricular infarction. Finally the influence of age must be considered. This, when it reduces the elasticity of the arterial tree and when it is accompanied by degenerative vascular changes in the brain, must sensitize the cerebrum to any reduction in blood flow. Severe general 
and focal cerebral symptoms in cardiac infarction, in the absence of any acute lesion in the arteries of the brain, have been described (Bean \& Read, 1942).

Of the five cases here reported with syncope or fit occurring after the onset of cardiac infarction, it was possible to establish the mechanism of the heart beat during the actual attack in one only (Case 13): in this a Stokes-Adams attack coincided with a period of complete heart block, the ventricular rate falling from 100 to 34; cardiac standstill did not occur. As the attack terminated the original rhythm and rate was resumed. In Case 12 complete block was present two hours after a syncopal attack, and although an irregular tachycardia had been noted immediately after the attack, this does not exclude the possibility that it was determined by block, as Case 13 shows. The incidence of complete block in cardiac infarction has been reported as 2 to 3 per cent (Kerr, 1937), but only a proportion of these have Stokes-Adams attacks or even syncopal symptoms.

Nodal rhythm was recorded in Case 11 immediately before a StokesAdams seizure, and was again recorded as soon as the convulsion had subsided though consciousness was not recovered and death occurred a few minutes later. A cerebral vascular complication, especially hæmorrhage, has to be considered here, but a further coronary occlusion with acute peripheral circulatory failure would fit in with the change in the ventricular complexes of the cardiogram after the attack.

In Case 14 syncopal attacks appeared on the third day of a cardiac infarct in a man who had slowly passed into a shocked condition. There was sinus tachycardia and short runs of auricular premature beats, the last suggesting that syncope was dependent on auricular paroxysmal tachycardia.

The Stokes-Adams attacks in Case 15 were peculiar in being preceded by great intensification of anginal pain which was located below the left scapula, the pulse at the same time becoming progressively weaker and slower. Cardiograms taken on three separate days between attacks all showed sinus tachycardia with normal A-V conduction, providing no clue to the mechanism involved. This might have been paroxysmal heart block with ventricular standstill except that in this condition the ventricle usually ceases abruptly without preliminary change in heart rate or force. (Parkinson, Papp, and Evans, 1941; Cookson, unpublished observation.) But in any attempt at an explanation the significance of the pain that heralded the attack must be taken into account and it may be that nervous reflexes arising in the heart were largely responsible. On this view the mechanism would be similar to that suggested for the initial syncopal symptoms.

No patient with syncope or Stokes-Adams seizures survived many days, indicating a prognosis even more serious than in the first group.

\section{Summary}

Among 200 patients with acute cardiac infarction, a syncopal or epileptiform attack was observed in 15. At the onset syncope occurred in ten, of whom five were aged 70 or more. They presented the appearance of severe 
peripheral circulatory failure, often combined with a slow heart rate but in one there was ventricular tachycardia. Pain might be absent or slight. In five the cardiogram showed abnormal rhythms of supraventricular origin. Posterior infarction was commoner than anterior. Six of the patients had died by the fourth month. Possible causes of the syncope are briefly discussed.

Syncope and fits in the course of cardiac infarction are reported in five patients whose average age was 69 . Two had suffered previously from anginal pain. Two had syncope and three had Stokes-Adams attacks. All five died within 29 days of the onset. Abnormal rhythms were recorded in four. Cardiograms during the actual attack showed complete heart block in one, and nodal rhythm with a change in the ventricular complex immediately after a short convulsion in another. Indirect evidence as to the mechanism underlying the attacks in the remaining cases is given.

\section{REFERENCES}

Bean, W. B., and Read, C. T. (1942). Amer. Heart J., 23, 362.

Boyd, L. J., and Werblow, S. C. (1937). Amer. J. med. Sci., 194, 814.

Cushing, E. H., Feil, H. S., Stanton, E. J., and Wartman, W. B. (1942). Brit. Heart J., 4, 17. Gorham, L. W., and Martin, S. J. (1938). Arch. intern. Med., 62, 821.

Gross, H., and Sternberg, W. H. (1939). Arch. intern. Med., 64, 249.

Gross, L.(1921). The Blood Supply to the Heart. New York.

Hay, J. (1933). Lancet, 2, 787.

Kennedy, J. A. (1937). Amer. Heart J., 14, 703.

Kerr, J. D. O. (1937). Lancet, 2, 1066.

Parkinson, J., Papp, C., and Evans, W. (1941). Brit. Heart J., 3, 171. 